Metadata into High-Quality Records." Code4lib Journal no. 33 (July 2016): 1. http://journal.code4lib.org/

articles/11676

Wright, Jennifer. "Electronic Outages What Broke, Who Broke It, and How to Track It." Library Resources E Technical Services 60, no. 3 (July 2016): 204-213.

Submitted by

Anna Appleman, Cataloger

John Bulow Campbell Library, Columbia Theological Seminary

\title{
TESTIMONY
}

\section{Our Experience with Joining a Large Consortium}

I am the head of Technical Services at Covenant Theological Seminary, which in 1998 was a founding member of MOBIUS (originally an acronym for Missouri Bibliographic Information User System). This testimony is about our experience joining a large consortium, particularly the implementation of a complex ILS.

\section{MOBIUS}

The MOBIUS consortium currently has about 75 members, mostly Missouri academic institutions (with a few large public libraries and a few out-of-state members). Our union catalog is nearing 30 million items. Covenant was one of the 50 original founding libraries, but since the libraries implemented over several years, we did not actually "go live" on our Innovative Interfaces ILS until June 1, 2001.

MOBIUS is organized uniquely. The libraries are mostly grouped into 'clusters' which are, for the most part, geographical. Covenant belongs to the Bridges cluster, which includes academic libraries in the St. Louis area except for the community colleges (organized into their own cluster), and the large institutions such as Washington University, etc. which are not in clusters. Each cluster shares an OPAC among its members. The Bridges cluster is a diverse group of ten members or eleven libraries, including 7 universities and 4 seminaries (Covenant, Concordia, Kenrick-Glennon, and Eden).

\section{Why did we decide to join MOBIUS?}

We were ecstatic when MOBIUS was founded! The state of Missouri contributed over $\$ 11$ million for the startup and more funds for several years. We had been struggling to upgrade our technology and the OPAC that was within our budget was woefully inadequate to support graduate level research. The state funds paid most costs for bringing up the Innovative Interfaces Inc. (III) system and for upgrading equipment, migrating records to III's OPAC (which is integrated into the statewide III InnReach union catalog), providing many days of training by III trainers, and we had MCO (MOBIUS Central Office) staff who shepherded us through the process of implementation. All the help and coaching we had was tremendously helpful. We have never regretted our decision.

By joining MOBIUS we were able to implement an extremely robust ILS. As a cataloguer, in particular, I have appreciated all the advanced editing capabilities, such as global updating, that a large system offers. The state of Missouri no longer supports MOBIUS financially, but the annual costs are partly based on student FTE, so it is still affordable for us.

\section{Migration Complexity}

Migrating to a different ILS is not easy or straightforward. It is especially difficult if you have a small staff (5 full-timers) and can't hire any extra assistance. We didn't have the luxury of a project leader or implementation team; we just had to 
fit it into our normal workload. We had just finished a massive construction project and had a few weeks to bask in that accomplishment before the numbingly long work weeks during the implementation. In the end, it was worth it!

\title{
Managing a Migration
}

To migrate well takes time and attention. Attitude makes all the difference. Look at migrating as an opportunity, and as a chance for professional growth, not just as a painful slog. Do as much as you can to prepare in advance. Do your research. We interviewed librarians from a library that had migrated from the same OPAC we were using to III's OPAC. Their advice was invaluable. It enabled us to do some strategic data cleanup before we began implementation, which saved us much agony later on. Expect a lot of data cleanup. Any local workarounds you developed through the years for your current system will probably be a thorn in your side, so clean them up ahead of time as much as possible.

\section{Decisions, decisions, decisions!}

The implementation of III involved going through untold pages of work-forms. Because of the way MOBIUS is organized in clusters, the Bridges libraries had to make all these decisions together, since we share one local OPAC (which feeds into the consortium-wide union catalog). The Bridges cataloguers and site coordinators met every Friday for a day-long meeting for two months to hash out all these decisions. For example, how many separate indexes did we want? In addition to the usual (Author, Title, etc.), we opted for adding a separate Series index and a Journal title index. What MARC fields were to be mapped in each index? Which MARC fields were to be included in the Keyword index? What about subfield indexing? And so on, and so on, worksheet after worksheet. We didn't always agree at first, but because we were fully committed to creating a catalog that worked for every Bridges library, we eventually hammered out solutions that we were all satisfied with.

We had our own local decisions as well. One was to hold off on implementing certain modules. We were still using our own Microsoft Access database for acquisitions and our serials records were still in paper. With III, we gained access to Circulation, Serials and Acquisition modules, in addition to Cataloging. But we started just with Circulation and Cataloging. As we felt we were getting these under control, we implemented Acquisitions and eventually Serials.

\section{After Implementation}

How does one achieve success as a small institution in a big consortium? Get involved at every level. I was on the MOBIUS cataloging committee for years and on almost every task force that had anything to do with cataloging. The other Covenant librarians have also served in various capacities at the consortium level. As a result, we are known and our opinions count and are occasionally sought out. This has been very important when decisions affecting the union catalog structure have been discussed.

\section{Unexpected Benefits}

The most surprising result of our implementation to me is the professional friendship I have formed with the other Bridges cataloguers. I appreciate my ATLA colleagues greatly, but it has been wonderful also to have nearby colleagues. I had always worked as the only cataloguer in the library and now I have a cadre of colleagues, working in the same system. We have an active Bridges cataloguers' committee that meets 4 times/year. We share our problems, our solutions, and train each other as we learn new things. They are a real blessing to me.

\author{
Submitted by \\ Denise Pakala, Associate Librarian for Technical Services \\ Buswell Library, Covenant Theological Seminary
}

